\title{
Levels of interleukins 12 (IL-12) and 13 (IL-13), hepatitis B and C serology, and blood cultures among acute myeloid leukemia (AML) patients in Egypt
}

Nour el deen RAA (1), Harfoush RA (1), Elgharabawy MM (1), Hamed NA (2), Morsi MG (1)

(1) Department of Microbiology and Immunology, School of Medicine, Alexandria University, Egypt; (2) Department of Internal Medicine, School of Medicine, Alexandria University, Egypt.

\begin{abstract}
There is an interest in the use of IL-12 as a possible anti-cancer drug to induce immune responses and anti-IL-13 formulations to treat the undesirable effects of IL-13. Thus, the present study aimed at analyzing IL-12 and IL-13 profiles, viral hepatitis serology and blood cultures in acute myeloid leukemia (AML) patients. Forty individuals ( 20 without septicemia - Group A, and 20 with septicemia - Group B) and 20 healthy controls were evaluated. Hepatitis B virus antigens ( $\mathrm{HBsAg}$ ) and hepatitis $C$ virus antibodies (HCV Ab) were quantified using commercial ELISA kits. IL-12 and IL-13 levels were estimated in culture supernatant of mitogen-stimulated peripheral blood mononuclear cells by ELISA. Significantly low IL-12 values were observed among AML patients compared to controls whereas the opposite was observed regarding IL-13. IL-12 levels were found to be elevated in the follow-up cases. M4 and M5 subtypes of AML presented higher IL-12 levels than M1 and M2 subtypes. The isolated organisms from AML with septicemia were Staphylococcus aureus (35\%), Esherichia coli (25\%), coagulase-negative staphylococci (25\%), and Candida (15\%). Fungemia cases showed higher IL-12 values than bacteremia cases. In conclusion, IL-12 and IL-13 should be further tested in large-scale studies to provide future immunotherapy against AML.
\end{abstract}

Key words: acute myeloid leukemia, IL-12, IL-13, HBsAg, HCV, ELISA.

\section{INTRODUCTION}

Acute myeloid leukemia (AML) is a cancer of the myeloid line of blood cells. The myeloid stem cells in AML develop into myeloblasts (1).

Although conventional cancer treatments (surgery, chemotherapy, and radiation) have greatly enhanced patients' survival rates, the manipulation of the immune response to cancer cells in order to promote their destruction remains an important and increasingly realistic goal for physicians. The ideal result of immunotherapy would be the specific eradication of cancer cells with minimal damage to normal host cells (2).

Cytokines have been used as vaccine adjuvants in antitumor vaccines. Interleukin 2 (IL-2) and interleukin 12 (IL-12) have been promising in conferring improved T-helper 1 (TH1) type immune responses to various tumor antigens (1).

In cancer therapy, cytokines are used to enhance immunity. Cytokines regulate both the innate and adaptive immune system. They appear to have applications in the treatment of hematological malignancies. The major cytokines currently in use or under evaluation for cancer therapy are: interferon- $\alpha$, IL-2, granulocyte macrophage-colony stimulating factor (GMCSF), and IL-12(3).

IL-12 is a very exciting cytokine. It is a heterodimeric protein that promotes $\mathrm{NK}$ and $\mathrm{T}$ cell activity and is a growth factor for B cells. IL12 shows promise in immunotherapy, both as an adjuvant therapy and in combination with other cytokines (4). 
IL-13 stimulates growth and differentiation of B-cells, inhibits TH1-cells and the production of macrophage inflammatory cytokines (e.g. IL-1, IL-6), and decreases the production of IL-8, IL-10 and IL-12 (5). Studies have shown that IL-13 release by activated T cells increased in the presence of AML blasts. Formulations suitable for treatment of disorders associated with undesirable expression or activity of IL13 are provided in different forms of anti-IL-13 antibody formulations $(6,7)$.

The present study aimed at analyzing cytokine profiles, viral hepatitis serology and blood cultures among AML patients in pursuit of future effective immunotherapy.

\section{PATIENTS AND METHODS}

The study was carried out on 40 patients suffering from AML admitted to Alexandria Main University Hospital during the years of 2008 and 2009. A group comprising 20 healthy subjects of matched age and sex served as controls. Group A consisted of 20 AML patients without septicemia whereas Group B was composed of 20 AML patients with septicemia.

Patients were subjected to the following: history taking, full clinical assessment, bone marrow examination, and abdominal ultrasound. Both patients and controls were subjected to: complete blood count (CBC); liver and renal function tests; and detection of HBsAg and HCV Ab using enzyme linked immunosorbant assay (ELISA) kits (Ortho Antibody to HBsAg ELISA Test System $2^{\circledR}$, Ortho-Clinical Diagnostics, USA; Ortho HCV version 3.0 ELISA ${ }^{\oplus}$ ). Conventional blood cultures for patients suffering from septicemia were performed. Cases and controls positive for human immunodeficiency virus (HIV) were excluded from the study.

Estimation of IL-12 and IL-13 levels was achieved by isolation of peripheral blood mononuclear cells (PBMC) from heparinized venous blood by Ficoll-hypaque (Sigma Aldrich, Australia) density layer centrifugation and cultured at $2 \times 10^{5}$ cells per $500 \mu \mathrm{L}$ RPMI- 1640 (Roswell Park Memorial Institute medium, Sigma Aldrich, Australia) medium supplemented with antibiotics and 5\% fetal calf serum (FCS). For stimulation, $5 \mu \mathrm{g} / \mathrm{mL}$ phytohemagglutinin (PHA, Wellcome Pharmaceuticals, UK) mitogen was used. Incubation of cultures was performed at $37^{\circ} \mathrm{C}$ in a humidified atmosphere of $5 \% \mathrm{CO}_{2}$. After two days of culturing, supernatants were collected from each tube and stored at $-20^{\circ} \mathrm{C}$ to be assayed using commercial ELISA kits [Human IL-12 $(\mathrm{P} 70)^{\oplus}$, Human IL-13 ${ }^{\circledR}$, RayBio, $\mathrm{UK}$ ] (8). For HBsAg and $\mathrm{HCV} \mathrm{Ab}$ a third generation ELISA (Ortho-Clinical Diagnostics, USA) $(9,10)$ was performed according to the manufacturers' instructions. Bacteremia was detected by the conventional blood culture technique (11).

\section{Statistical Analysis}

The statistical package for social science (SPSS version 9.0 for Windows ${ }^{\circledast}$ Microsoft, USA) was used for data analysis. Comparison between patients and controls was made using the t-test for quantitative data and $\chi^{2}$-test for qualitative data. The Kruskal-Wallis test was used to test for differences among the three studied groups. The Mann-Whitney test was used to ascertain any differences between control and other groups. The $5 \%$ level of significance was adopted, so that $p \leq 0.05$ was considered significant. Data were shown as mean \pm standard deviations (SD).

\section{RESULTS}

The studied subjects were three different groups: a healthy control group $(n=20)$; Group A - AML patients without septicemia $(n=20)$; and Group B: AML patients with septicemia $(\mathrm{n}=20)$.

Complete blood count (CBC) showed significantly higher white blood cell (WBC) count among cases compared to controls. The reverse was observed in hemoglobin level and platelet counts (Table 1).

Liver function tests showed mean values of $70.90 \mathrm{U} / \mathrm{L}$ for aspartate aminotransferase (AST) and $76.20 \mathrm{U} / \mathrm{L}$ for alanine aminotransferase (ALT) among Group A. Group B showed means of 110.05 U/L for AST and 109.3 U/L for ALT. Both values were significantly higher than the controls (AST: 18.37 U/L and ALT: 13.92 U/L).

Concerning renal function, groups $\mathrm{A}$ and $\mathrm{B}$ showed respective means of $18.15 \mathrm{mg} / \mathrm{dL}$ and $36.45 \mathrm{mg} / \mathrm{dL}$ for blood urea and $0.94 \mathrm{mg} / \mathrm{dL}$ and $2.82 \mathrm{mg} / \mathrm{dL}$ for serum creatinine. The values in both groups were higher than the controls (blood urea: $13.28 \mathrm{mg} / \mathrm{dL}$ and serum creatinine: 0.87 $\mathrm{mg} / \mathrm{dL})$. 
Table 1. Comparison of WBC count, hemoglobin values $(\mathrm{Hb})$ and platelet count among the studied groups

\begin{tabular}{|c|c|c|c|c|}
\hline & Controls & Group A & Group B & $X^{2}(p)$ \\
\hline \multicolumn{5}{|l|}{ WBC $\left(\times 10^{9} / L\right)$} \\
\hline Range & $4.50-9.80$ & $0.46-40.00$ & $14.40-40.00$ & \multirow{2}{*}{$(<0.001)$} \\
\hline Mean \pm SD & $7.87 \pm 1.42$ & $19.17 \pm 9.85$ & $22.00 \pm 7.17$ & \\
\hline $\mathrm{Z1}(p)$ & & $(<0.001)$ & $(<0.001)$ & \\
\hline \multicolumn{5}{|l|}{$\mathrm{Hb}(\mathrm{g} / \mathrm{dL})$} \\
\hline Range & $12.00-17.70$ & $4.0-11.60$ & $6.20-10.40$ & \multirow{2}{*}{$(<0.001)$} \\
\hline Mean $\pm S D$ & $14.76 \pm 1.79$ & $6.97 \pm 1.53$ & $8.06 \pm 1.24$ & \\
\hline $\mathrm{Z1}(p)$ & & $(<0.001)$ & $(<0.001)$ & \\
\hline $\mathrm{Z2}(p)$ & & & $(0.006)$ & \\
\hline \multicolumn{5}{|c|}{ Platelets (x 109/L) } \\
\hline Range & $210.00-324.00$ & $90.00-340.00$ & $90.00-290.00$ & \multirow{2}{*}{$(<0.001)$} \\
\hline Mean \pm SD & $282.45 \pm 32.71$ & $211.50 \pm 72.71$ & $190.00 \pm 59.91$ & \\
\hline $\mathrm{Z1}(p)$ & & $(0.001)$ & $(<0.001)$ & \\
\hline
\end{tabular}

$X^{2}$ : chi-square for Kruskal Wallis test; Z1: Z for Mann Whitney test between controls and other groups; Z2: Z for Mann Whitney test between Group A and Group B; $p$ : statistically significant at $p \leq 0.05$

Table 2. Comparison of the three study groups according to hepatitis B and C serological markers

\begin{tabular}{|c|c|c|c|c|c|c|c|}
\hline & \multicolumn{2}{|c|}{ Controls } & \multicolumn{2}{|c|}{ Group A } & \multicolumn{2}{|c|}{ Group B } & \multirow{2}{*}{$X^{21}(p)$} \\
\hline & $\mathrm{N}$ & $\%$ & $\mathrm{n}$ & $\%$ & $\mathrm{n}$ & $\%$ & \\
\hline \multicolumn{8}{|l|}{$\mathrm{HBsAg}$} \\
\hline Absent & 20 & 100.0 & 13 & 65.0 & 14 & 70.0 & \multirow{2}{*}{$(0.015)$} \\
\hline Present & 0 & 0.0 & 7 & 35.0 & 6 & 30.0 & \\
\hline FEp & & & \multicolumn{2}{|c|}{$0.008^{*}$} & \multicolumn{2}{|c|}{$0.020^{*}$} & \\
\hline \multicolumn{8}{|c|}{ Anti-HCV Ab } \\
\hline Absent & 20 & 100.0 & 12 & 60.0 & 13 & 65.0 & \multirow{2}{*}{$(0.006)$} \\
\hline Present & 0 & 0.0 & 8 & 40.0 & 7 & 35.0 & \\
\hline FEp & & & \multicolumn{2}{|c|}{$0.003^{*}$} & \multicolumn{2}{|c|}{$0.008^{*}$} & \\
\hline \multicolumn{8}{|c|}{$\begin{array}{c}\text { HBsAg and anti- } \\
\text { HCV Ab }\end{array}$} \\
\hline Absent & 20 & 100.0 & 14 & 70.0 & 15 & 75.0 & \multirow{2}{*}{$(0.032)$} \\
\hline Present & 0 & 0.0 & 6 & 30.0 & 5 & 25.0 & \\
\hline FEp & & & \multicolumn{2}{|c|}{$0.020^{*}$} & \multicolumn{2}{|c|}{$0.047^{*}$} & \\
\hline
\end{tabular}

$\mathrm{X}^{21}$ : chi-square test between the different studied groups; FEp: $p$ value for Fisher Exact test between control and other groups; *: statistically significant at $\mathrm{p} \leq 0.05$. 
Table 3. IL-12 and IL-13 levels among the studied groups

\begin{tabular}{|c|c|c|c|c|}
\hline & Controls & Group A & Group B & $x^{2}(p)$ \\
\hline \multicolumn{5}{|l|}{ IL-12 (pg/dL) } \\
\hline Range & $10.03-69.11$ & $8.03-58.39$ & $8.03-50.37$ & \multirow{2}{*}{$(0.491)$} \\
\hline Mean \pm SD & $24.48 \pm 14.33$ & $20.89 \pm 14.36$ & $22.06 \pm 14.14$ & \\
\hline \multicolumn{5}{|l|}{ IL-13 (pg/dL) } \\
\hline Range & 2.56- 19.72 & $0.0-0.2$ & $0.0-0.0$ & \multirow{2}{*}{$(<0.001)$} \\
\hline Mean \pm SD & $10.58 \pm 4.91$ & $0.002 \pm 0.01$ & $0.001 \pm 0.0001$ & \\
\hline Z1 $(p)$ & & $(<0.001)$ & $(<0.001)$ & \\
\hline
\end{tabular}

$\mathrm{X}^{2}$ : chi-square for Kruskal Wallis test; Z1: Z for Mann Whitney test between control and other groups.

Thirty percent (30\%) of Group A and 25\% of Group B were positive for both hepatitis B and hepatitis $\mathrm{C}$ serological markers. They were significantly higher than the controls. The levels of IL-12 and IL-13 in the patients' serum as well as those of the control group are shown in Table 3.

Microorganisms isolated from blood culture of AML cases (Group B) were Staphylococcus aureus $(\mathrm{n}=7,35 \%)$, Esherichia coli $(\mathrm{n}=5,25 \%)$, coagulase-negative staphylococci $(\mathrm{n}=5,25 \%)$ and Candida albicans $(\mathrm{n}=3,15 \%)$.

IL-12 levels were higher among cases positive for hepatitis B, C, or both. Their respective mean values were $24.57,23.86$, and $26.71 \mathrm{pg} / \mathrm{dL}$. As to IL-13, the levels were higher in cases negative for hepatitis $\mathrm{B}, \mathrm{C}$, or both. The mean values were $4.50,4.70$, and $4.32 \mathrm{pg} / \mathrm{dL}$, respectively.

Correlating interleukin levels and the isolated organisms from Group B revealed the highest IL-12 value with Candida albicans (34.38 pg/ dL) compared to $23.45 \mathrm{pg} / \mathrm{dL}$ with Stapylococcus aureus, $21.02 \mathrm{pg} / \mathrm{dl}$ with Escherichia coli, and 13.74 $\mathrm{pg} / \mathrm{dL}$ with coagulase-negative staphylococci.

\section{DISCUSSION}

The manipulation of the immune response to cancer cells in order to promote their destruction remains an important and increasingly realistic goal for physicians (3). Our results showed an inverse relation between platelets and IL-12 in the control group. Group A showed an inverse relation between IL-13 and hemoglobin values, and a positive correlation with platelet count. In another study, IL-12-induced PAF synthesis played a critical role in triggering the events involved in the mitogenic response of PMN and NK to IL-12 (12).

Anti-inflammatory cytokines - such as IL-13 - expression promote heme degradation and iron storage in monocytes and thereby contribute to iron storage in the reticuloendothelial system (13). Transmission of HBV infection through donated blood is reportedly very common, particularly in the developing world (14). Similarly, $26.6 \%$ among 188 blood donors were confirmed antiHCV positive by RIBA test in a study done in Cairo (15).

In developing countries, the primary sources of $\mathrm{HCV}$ infection are unsterilized injection equipment and infusion of inadequately screened blood and blood products (16). In our study, $35 \%$ of the cases in Group A as well as $30 \%$ of the cases in Group B tested positive for hepatitis B surface antigen. Forty percent of the cases in Group A and 35\% of Group B cases tested positive for Hepatitis $C$ virus antibodies. The percentages of cases positive for both hepatitis B and hepatitis C were $30 \%$ of Group A and $25 \%$ of Group B. All the cases in the study had a history of blood transfusion. One of the hazards of blood transfusion is infection with $\mathrm{HBV}$ or HCV (17). This could explain the significantly elevated liver enzymes detected in the present study. Furthermore, the fact that renal function tests were significantly elevated may constitute a side effect of chemotherapy (18).

The only positive significant correlation was between IL-12 and serum creatinine in Group B. In a study performed in Osaka, Japan, to assess the influence of IL-12 on several physicochemical characteristics of nephritogenic IgA molecules 
in HIGA mice, IL-12 administration caused slight increases in serum creatinine (19). Interleukin-12 plays a central role in the immune response as a cytokine whose functions bridge innate resistance and antigen-specific adaptive immunity. IL-12 is a T-cell-stimulating factor; it stimulates the production of IFN- $\gamma$ and TNF- $\alpha$ from $\mathrm{T}$ and NK cells, and reduces IL-4-mediated suppression of IFN- $\gamma$ (20). IL-12 also presents anti-angiogenic activity. Because of its ability to induce immune responses and its anti-angiogenic activity, there has been an interest in testing IL-12 as a possible anti-cancer drug (21). The subjects associated with elevated levels of serum IL-12 may express an immune response against tumor cells. The decrease in serum IL-12 in our cases may be attributed to immunosuppression after chemotherapy (22).

Direct injection of IL-12 has previously shown some effectiveness in the treatment of leukemia in animal models; however, human trials with this approach have not proven successful. Research at University Health Networks (UHN) has demonstrated that IL-12 delivered via transduced leukemia cells has a powerful anti-cancer effect. A key finding of this research is that a remarkably small number of IL-12-producing cells are required for effective therapy (23). IL-12 has been shown to exert potent immunostimulatory effects on certain helper T cells, as well as on cytotoxic T lymphocytes and NK cells. Preclinical studies suggest that IL-12 may prove useful in the treatment of several human diseases, including HIV infection and cancer (24-26). These properties suggest that IL-12 may play an important role in the immune response to many viruses, including HBV. It has been shown that HBV-specific cytotoxic $\mathrm{T}$ lymphocytes inhibit HBV replication in the livers of transgenic mice by a non-cytolytic process that is mediated in part by IFN-gamma. IL-12 may have therapeutic value as an antiviral agent for the treatment of chronic HBV infection (27).

$\mathrm{T}$ cell responses, including interferon- $\gamma$ production, are severely suppressed in chronic HCV patients. Researchers examined IL-12 production, which is critical for the induction of interferon- $\gamma$ synthesis, in lipopolysaccharidestimulated human monocyte/macrophages. It was found that core protein binds the $\mathrm{gClqR}$ displayed on the cell surface of monocyte/macrophages and inhibits the production of IL-12p70 upon lipopolysaccharide stimulation. These results suggest that the $\mathrm{HCV}$ core-gC1qR interaction may play a pivotal role in establishing persistent infection by dampening TH1 responses (28).

The role of IL-13 has been demonstrated to be prominent in malignancy. High levels of IL13 provoke reduced tumor immunosurveillance resulting in an uninhibited tumor progression. IL-13 has been applied in cancer treatment by the technology of Targepeutics, which involves genetically engineering the IL-13 molecule that is naturally present in the body to a modified form that binds the normal IL-13 receptor, but does not activate the signaling from the receptor. Thus, Targepeutics' compounds should effectively negate the role of endogenous IL-13 by a double mechanism of blocking receptors and inhibiting signaling. Neutralizing natural IL-13 has demonstrated a marked increase in the body's ability to fight off cancer cells and tumors (29). It had been reported that IL-13 had a direct and nontoxic inhibitory effect on constitutive AML blast cytokine secretion, and that the release of IL-13 by activated T cells was elevated in the presence of AML blasts (30).

A research study performed in Norway by Bruserud (31) evaluated the effects of the cytokines IL-4, IL-10 and IL-13 on AML and found them to have divergent effects on AML blast proliferation in vitro, and their final effect (enhancement/inhibition/no effect) depended on individual differences among patients and the presence of other exogenous cytokines. In contrast to these divergent effects on blast proliferation, all three cytokines were found to inhibit constitutive AML blast cytokine secretion independent of their effects on spontaneous blast proliferation. Bruserud (31) concluded that although exogenous G-CSF, GM-CSF and IL3 can modulate the effects of IL-4, IL-10, and IL-13 on AML blast proliferation, the IL4/IL10/ IL13-induced inhibition of AML blast cytokine secretion is not modulated or reversed by the presence of these exogenous hematopoietic growth factors (31).

In the present study, however, we detected a significant decline in IL-13 levels in cases compared to controls. This result may be due to the initiation of chemotherapy, or to cross infection with hepatitis B or hepatitis C. Seventyfive percent of the cases in Group A and 45\% of the cases in Group B were subjected to chemotherapy. 
IL-13 predominance in chronic HCV infection was found to have a role in the etiology of liver damage in which IL-13 was found to be one of the driving forces in fibrogenesis (32).

In the present study, blood culture specimens from Group B (AML with septicemia) yielded Staphylococcus aureus (35\%), Esherichia coli (25\%), coagulase-negative staphylococci $(25 \%)$, and Candida albicans (fungemia) (15\%). These results are in agreement with another study performed in Saudi Arabia which concluded that gram-positive microorganisms were the most common blood isolates followed by gramnegative bacteremic infections (33). Similarly, another study in Spain showed that grampositive microorganisms were found to be the cause in $70 \%$ of the episodes, with coagulasenegative staphylococcus (35\%) being the most frequently isolated microorganism, followed by Staphylococcus aureus (11\%) (34). According to another research study carried out in Japan that studied septicemia associated with AML, 52.3\% of the total isolates were gram-negative bacilli, $26.8 \%$ were gram-positive cocci, $17.2 \%$ were fungi, and $3.5 \%$ were anaerobic bacteria (35).

The variability in results in different studies could be attributed to environmental or geographical factors involved in the greater prevalence of certain microorganisms relative to others. The innate immune system plays a key role in immune surveillance against pathogens, particularly during the early phase of infection. The killing activity presented by NK cells has been shown to be up-regulated by several cytokines: e.g. IL-2, IL-12, IFN- $\alpha / \gamma$ and TNF $(36,37)$. To conclude, IL-12 and /or IL-13 can be exploited and tested on a large scale as future immunotherapy in AML.

\section{ACKNOWLEDGEMENTS}

Thanks are due to all staff members of the Department of Microbiology, colleagues and our parents who sponsored this study.

\section{COPYRIGHT}

(c) CEVAP 2011

\section{SUBMISSION STATUS}

Received: January 30, 2011.

Accepted: April 18, 2011.

Abstract published online: April 26, 2011.

Full paper published online: August 31, 2011.

\section{CONFLICTS OF INTEREST}

There is no conflict.

\section{ETHICS COMMITTEE APPROVAL}

The present study was approved by the Ethics Committee of Alexandria University, Egypt.

\section{CORRESPONDENCE TO}

MONA GAMAL MORSI, Department of Microbiology and Immunology, School of Medicine, Alexandria University, Egypt. Mobile: 0105171621. Email: morsirg@yahoo.com.

\section{REFERENCES}

1. Abeloff MD, Armitage JO, Niederhuber JE, Kastan MB, McKena WG. Acute myeloid leukemia. Clinical Oncology, $3^{\text {rd }}$ ed. Orlando: Churchill Livingstone; 2004.

2. Yanada M, Matsuo K, Suzuki T. Prognostic significance of FLT3 internal tandem duplication and tyrosine kinase domain mutations for acute myeloid leukemia: a meta-analysis. 2005;19(8):1345-9.

3. Estey EH. Therapeutic options for acute myelogenous leukemia. Cancer. 2001;92(5):1059-73.

4. Robin M, Schlageter MH, Chomienne C, Padua RA . Targeted immunotherapy in acute myloblastic leukemia: from animals to humans. Cancer Immunol Immunother 2005; 54(10):933-43.

5. Wynn TA. IL-13 effector functions. Annu Rev Immunol. 2003;21:425-56.

6. Jeha S, Giles FJ . Acute myeloid leukemia. ASH-SAP 2007:243-252.

7. Lauri JG. Immunologic weapons against acute myeloid leukaemia. Immunology. 2002;107(1):20-7.

8. Morsi MG, Atta HY, Rabie AK. Comparative study of different test systems for measuring cytokine production among tuberculous and healthy persons. Egypt J Immunol 1998;5(1):153-62.

9. Valentine-Thon E, Van Loon AM, Schirm J, Reid J, Klapper PE, Cleator GM. European proficiency testing program for molecular detection \& quantitation of hepatitis B virus. J Clin Microbiol. 2001;39(12):440712.

10. Tobler LH, Stramer SL, Lee SR, Masecar BL, Peterson JE, Davis EA, et al. Impact of HCV 3.0 EIA relative to HCV 2.0 EIA on blood donor screening. Transfusion. 2003;43(10):1452-9.

11. Collee JG, Duguid JP, Fraser AG, Marmian BP, Simmons A. Laboratory strategy in the diagnosis of infective syndromes. In: Collee JG, Duguid JP, Fraser AG, Marmian BP, Simmons A, eds. Mackie \& McCartney: Practical Medical Microbiology. $14^{\text {th }}$ ed. London: Churchill Livingstone; 1996. p. 53-94.

12. Bussolati B, Mariano F, Cignetti A, Guarani A, Cambi $\mathrm{V}$, Foà $\mathrm{R}$, et al. Platelet-activating factor synthesized by IL-12 stimulated polymorphonuclear neutrophils and NK cells mediates chemotaxis. J Immunology. 1998;161(13):1493-500. 
13. Lee TS, Chau LY: Heme oxygenase-1 mediates the anti-inflammatory effect of interleukin-10 in mice. Nat Med. 2002;8(3):240-6.

14. Jules L, Dienstag MD. Hepatitis B virus infection. N Eng J Med. 2008;359(14):1486-500.

15. Pybus OG, Drummond AJ, Nakano T, Robertson $\mathrm{BH}$, Rambaut A. The epidemiology and iatrogenic transmission of hepatitis C virus in Egypt: A Bayesian coalescent approach. Mol Biol Evol 2003;20(3):381-7.

16. Meier V, Ramadori G. Hepatitis C virus virology and new treatment targets. Expert Rev Anti Infect Ther.2009; 7(3):329-50.

17. Alter HJ, Klain HG. The hazards of blood transfusion in historical perspective. Blood. 2008;112(7):2617-26.

18. Kintzel PE, Dorr RT. Anticancer drug renal toxicity and elimination: dosing guidelines for altered renal function. Cancer Treat Rev. 1995;21(1):33-64.

19. Kobayashi I, Nogaki F, Kusano H, Ono T, Miawaki $\mathrm{S}$, Yoshida $\mathrm{H}$, et al. Interleukin-12 alters the physicochemical characteristics of serum and glomerular IgA and modifies glycosylation in a ddY mouse strain having high IgA levels. Nephrol Dial Transplant. 2002;17(12):2108-16.

20. Tricheri G. Interleukin-12 and the regulation of innate resistance and adaptive immunity. Nat Rev Immunol. 2003;3(2): 133-46.

21. Dunussi-Joannopoulos K, Runyon K, Erickson J, Schaub RG, Hawley RG, Leonard JP. Vaccines with interleukin-12 transduced acute myeloid leukemia cells elicit very potent therapeutic and long-lasting immunity. Blood. 1999;94(12):4263-73.

22. Osama S, Shamaa S, AL-Tonbary Y. The impact of some cytokines in patients with acute leukemia and lymphoma. $23^{\text {rd }}$ International Congress of Pediatrics, Beijing, China, 2001; 9-14.

23. Labbe A, Nelles $M$, et al. IL-12 Immunotherapy of murine leukemia. Comparison of systemic versus gene modified cell therapy. J Cell Mol Med. 2009;13(8B):1962-76

24. Trinchieri G. Interleukin-12: a cytokine produced by antigen-presenting cells with immunoregulatory functions in the generation of T-helper cells type 1 and cytotoxic lymphocytes. Blood. 1994;84(12):4008-27.

25. Wolf SF, Sieburth D, Sypek J. Interleukin 12: a key modulator of immune function. Stem Cells. 1994;12(2):154-68.

26. Hendrzak JA, Brunda MJ. Interleukin 12. Biologic activity, therapeutic utility, and role in disease. Lab Invest. 1995;72(6):619-37.
27. Cavanaugh VJ, Guidotti LG. Interleukin-12 inhibits hepatitis B virus replication in transgenic mice. J Virol.1997;71(4):3236-43.

28. Eisen-Vandervelde AL, Wagganer SN, Yao ZQ, Cale EM, Hahn CS, Hahn YS. Hepatitis C virus core selectively suppresses interleukin 12 synthesis in human macrophages by interfering with AP-1 activation. J Biol Chem. 2004; 279(42):43479-86.

29. Targepeutics. Cancer immunotherapy. Targeting using genetically engineered IL-13. Available from: www. targepeutics.com/ci.htm. Cited: June 2010.

30. Bruserud O. Effects of interleukin-13 on cytokine secretion by human acute myelogenous leukemia blasts. Leukemia. 1996;10(9):1497-503.

31. Bruserud O. Interleukin 4 (IL4), IL 10, and IL 13 inhibit in vitro cytokine secretion by acute myelogenous leukemia blasts in the presence of exogenous haematopoietic growth factors. Haematol. 1998;3:44350.

32. Weng HL, Liu Y, et al. The etiology of liver damage imparts cytokines transforming growth factor beta 1 or interleukin-13 as driving forces in fibrogenesis. Hepatology. 2009;50(1):230-43.

33. Bone RC, Balk RA, Cerra FB, et al. Definitions for sepsis and organ failure and guidelines for the use of innovative therapies in sepsis. The ACCP/SCCM Consensus Conference Committee. American College of Chest Physicians/Society of Critical Care Medicine. Chest. 1992;101(6):1644-55.

34. Rubio M, Palau L, Vivas JR, del Porto E, DiazMediavilla J, Alvarez A, et al. Predominance of grampositive microorganisms as a cause of septicemia in patients with haematological malignancies. Infect Control Hosp Epidemiol. 1994;15(2):101-4.

35. Yakota T, Teshima H, Okajima Y, Tsuboi A, Oji A, Karasuno T, et al. Septicemia associated with hematopoietic disorders and its features according to respective primary disorders. Kansenshogaku Zasshi. 1996; 70(2):108-15.

36. Orange JS, Biron CA. Characterization of early IL-12, IFN- $\alpha \beta$, and TNF effects on antiviral state and NK cell responses during murine cytomegalovirus infection. J Immunol. 1996;156:4746-56.

37. Carson WE, Giri JG, Lindemann MJ, et al. Interleukin(IL) 15 is a novel cytokine that activates human natural killer cells via components of the IL-2 receptor. J Exp Med. 1994;180(4):1395-403. 